Михаил Яковлевич Дымарский

Россия, Российский государственный педагогический университет им. А.И. Гериена ИЛИ РАН

\title{
Интонационный принцип русской пунктуации и его применение в формулировках правил ${ }^{1}$
}

Ключевые слова: пунктуация, принципы, интонация, интонационный принцип, правило, интонационные конструкции.

Key words: punctuation, principles, intonation, intonation principle, rule, intonation constructions.

\section{Abstract}

The article briefly reviews the history of the intonation principle in Russian punctuation. It is shown that, despite its spontaneous partial consideration in the early period of the formation of Russian punctuation, its theoretical justification and inclusion in the list of punctuation principles occurred only in the $20^{\text {th }}$ century. The actual status of this principle in the current punctuation rules is characterized as paradoxical, since the declaration of reliance on the intonation principle is not supported by its real consideration in the wording of the rules. Using an example of a group of rules governing the setting of the $\mathrm{m}$-dash in a binominative sentence, it is shown that relying on the intonational marking of communicative components in a sentence can considerably simplify and reduce the formulation of rules.

Интонационный принцип традиционно считается одним из трех принципов, на которые опирается русская пунктуация - наряду со структурным и смысловым. B [Lopatin 2009] эта триада заменена диадой: семантико-синтаксический и семантико-интонационный принципы, - что можно трактовать в том смысле, что, хотя во главу угла безоговорочно поставлено семантическое начало, за интонацией сохранен статус одной из важнейших детерминант пунктуации. При этом, однако, в действующих правилах упоминания об интонации

1 Работа выполнена при поддержке РФФИ, проект № 18-012-00778 «Теоретические основания кодификации русской пунктуации». 
единичны даже в тех разделах, где они диктуются самим материалом: например, в параграфах, посвященных знакам конца предложения, слова с основой интонац- встречаются лишь дважды. В разделе, посвященном пунктуации в бессоюзных сложных предложениях, слово интонация и его производные не встречаются ни разу.

Между тем учет интонационного оформления позволяет заметно упростить существующие группы правил, что и будет показано ниже.

В статусе теоретически осмысленного интонационный принцип появился в числе принципов пунктуации позже других, хотя в роли естественного основания пунктуации первенство было, по-видимому, именно за интонацией в неразрывной связи со смысловым критерием. Точнее - за тем компонентом интонации, который связан с паузированием: достаточно вспомнить об Аристофане Византийском (ок. 257-180 гг. до н.э.), система которого состояла из трех точек, располагаемых внизу, в середине или в верхней части строки в зависимости от долготы требуемой паузы [Golubeva, Gorbova 2020: 87]. Долгота же паузы определялась тем, конец колона, периода или еще более крупного фрагмента она должна была маркировать: не случайно сам Аристофан именовал свою систему «колонометрией» (см.: https://ru.wikipedia.org/wiki/ Аристофан_Византийский). Этот же принцип: пауза по смыслу влечет знак препинания - сохранялся в течение многих веков и в русской книжно-письменной традиции, ср. показательную характеристику: «Ориентиром для писца служил смысл высказывания, и точки ставились для выделения смысловых частей, или синтагм. Таким образом, первоначально русская пунктуация была более „интонационной” и близкой к разговорной речи» [Golubeva, Gorbova 2020: 90; полужирный шрифт мой - М.Д.].

В русских грамматических трудах XVI-XVII вв., по утверждению M.В. Диваковой, знаки препинания связывались с интонацией [Divakova 2005] - но это утверждение следует читать в том же смысле: речь идет только о паузировании. Автор ссылается на сочинение «О грамотики инока Максима Грека Святогорца объявлено на тонкословие», опубликованное И.В. Ягичем и входящее в число приписываемых Максиму Греку (1470-1556), и пишет: «М. Грек подчеркивает лишь интонационное значение в употреблении знаков препинания. В то же время он пытается конкретизировать их использование, разграничивая функции запятой и точки с запятой» [Divakova 2005]. Данное сообщение, особенно частицу лишь в его составе, приходится признать не вполне заслуживающим доверия. Если учесть, что основное внимание автор XVI в. уделял тонкостям греческого ударения и придыхания, чтобы исключить ошибки, связанные с незнанием многими русскими переводчиками этих тонкостей [Ivanov 1976: 179-180], то становится понятно, что замечания Максима Грека о функциях запятой и точки с запятой не были развернутыми. Более того, внимание к интонационному началу в рекомендациях преподобного Максима можно усмотреть только в том замечании, что запятая 
(«иподиастоли») «должна была дать говорящему передышку при чтении» [Fedorova 2010; Gaevskaâ 1973: 8]; точка же должна была маркировать конец предложения, а только что появившаяся точка с запятой в русском языке употреблялась - под влиянием греческого, поддержанным авторитетом Максима Грека - в функции вопросительного знака.

У Мелетия Смотрицкого, система которого включала уже 10 знаков препинания, находим следующую картину: первые три знака - «черта», «запятая», «двоточие»- ставятся в связи с «отдохом» и образуют иерархию, сильно напоминающую систему Аристофана Византийского; все остальные знаки так или иначе связаны со смыслом («разумом») и/или синтаксической структурой [Smotrickij 1619/2000: 152-153].

Неудивительно, что в эпоху формирования научных представлений, более близких к современным, картина была уже существенно иной. Если смысловой и структурный принципы сформулированы в «Российской грамматике» М.В. Ломоносова вполне отчетливо («Строчные знаки ставятся по силе разума и по его расположению и союзам» [Lomonosov 1755: 60]), то первое явное упоминание об интонационном принципе появляется, по-видимому, только в XX в. Правда, Н.С. Валгина пишет, что интонационное начало лежало в основе пунктуационных представлений Я.К. Грота: «Основа пунктуации Я.К. Грота - логическое членение речи, передающееся в устной речи паузами и интонацией. Я.К. Грот стремился изучить интонационное оформление речи и паузы различной длительности, соответствующие логическому делению речи» [Valgina 1973]. Это сообщение любопытно тем, что если первая его часть очевидным образом опирается на формулировку самого Грота: «В живой речи логическое отношение между словами обозначается интонациею и приостановками голоса (паузами). На письме к означению таких пауз служат знаки препинания» [Grot 1899: 785], - то опору его второй части ни в [Grot 1899], ни в [Grot 1894] обнаружить не удаётся (в самом учебнике Н.С. Валгиной ссылки на источник утверждения нет). Мысль об интонационной основе пунктуации как таковой была, возможно, Я.К. Гроту близка, но показательно разграничение в его собственной формулировке интонации и паузирования - и связывание знаков препинания только с последним. От мысли же ввести опору на интонацию в правила пунктуации он был далек и при формулировании этих правил учитывал, как - в данном случае уже справедливо - пишет Н.С. Валгина, «прежде всего синтаксическое строение предложения и смысловые отношения между его частями» [Valgina 1973]. Поэтому формулирование интонационного принципа пунктуации следует связывать все-таки с именами А.М. Пешковского и Л.В. Щербы.

Первый из них, как известно, писал: «Несмотря на упорное стремление грамматистов в течение многовековой истории знаков препинания прикрепить их к определенным грамматическим понятиям и правилам, они и поныне отражают, по моему убеждению, в огромном большинстве случаев, 
не грамматическое, а декламационно-психологическое расчленение речи» [Peškovskij 1918: 107]. Внимательное чтение этой работы убеждает в том, что замечательный ученый и здесь намного опередил свое время: ведь под «декламационными фигурами» он подразумевал то, что через полвека станет широко известно как интонационные конструкции [Bryzgunova 1980], а еще через несколько десятилетий будет осмыслено как набор стандартных акцентов, маркирующих коммуникативные составляющие предложения [Ânko 2001; Padučeva 2015; Cimmerling 2016]. Чтобы в этом убедиться, достаточно привести, например, следующий фрагмент: «Я не могу входить здесь в подробности той декламационной фигуры, которая обозначается точкой. Могу только сказать, что в общем ее можно охарактеризовать как спокойное, заключительное понижение голоса с последующей паузой...» [Cimmerling 2016: 109]. Не нужно особой проницательности, чтобы узнать в этой характеристике ИК-1. Далее в этой работе А.М. Пешковский характеризует еще целый ряд «декламационных фигур», которые соотносятся с ИК-3, ИК-3Э (эмфатической, по [Ânko 2001: 64 сл.]), ИК-6 и др. Можно не сомневаться в том, что А.М. Пешковский был одним из тех, кого полвека спустя А.А. Реформатский, рассуждая о теоретических основах изучения интонации, не без иронии называл «теми, кто верит, что пунктуация - это письменная передача интонационных возможностей устной речи» [Reformatskij 1971: 100].

Что же касается Л.В. Щербы, то в широко известной статье, написанной для «Литературной энциклопедии», он определял пунктуацию как «правила употребления дополнительных письменных знаков (знаков препинания), служащих для обозначения ритмики и мелодики фразы, иначе фразовой интонации» [Ŝerba 1935: 366; разрядка оригинала], т.е. ставил интонацию во главу угла. Однако далее в этой статье Л.В. Щерба вынужден признать, что в реальности более существенную роль играет «идеографический» (смысловой) принцип, а знаки препинания иногда прямо противоречат действительной интонационной структуре фразы (например, запятая в сочетании существительного с атрибутивным придаточным дом, где я живу не отражает ни паузы, ни сколько-нибудь значимого движения тона) [Ŝerba 1935: 367].

Таким образом, в теории пунктуации сложилась парадоксальная ситуация: крупнейшие специалисты единодушно признают важнейшую роль интонационного принципа - и при этом в сводах правил пунктуации упоминания об интонации единичны, о чем уже сказано выше. Эта ситуация была ощутима почти полтора столетия назад (ср. размышления Я.К. Грота) - и существует поныне. Чем это можно объяснить? Если вернуться в конец XIX в., то объяснение, безусловно, в том, что изучение интонации русского предложения находилось в зачаточном состоянии. Но если оценивать эту ситуацию с позиций конца первой четверти XXI в., то объяснение в том, что при составлении пунктуационного свода не учитывается то, что находится буквально 
под руками, то, о чем Я.К. Грот мог бы только мечтать и что с удивительной прозорливостью предвосхитил А.М. Пешковский.

В ныне действующих правилах безусловное действие интонационного принципа ограничивается, пожалуй, лишь правилами выбора знака в конце предложения, когда ни синтаксическая структура, ни учет смысла наличных в конструкции слов неспособны продиктовать знак:

(1) Да.

(2) Да!

(3) Да?!

(4) Дак..

Поэтому и суть интонационного принципа нередко сводится к тому, что выбор знака именно в подобных случаях объясняется интонацией, хотя формулировка этого принципа в том же источнике, откуда заимствованы примеры (1-4), казалось бы, не исключает и более широкой трактовки: сообщается, что это «подчиненный принцип пунктуации, который предписывает знаки в предложении ставить в соответствии с особенностями интонации» [Surikova 2009].

В цитированной формулировке показательно определение «подчиненный». Оно отражает взгляд значительного количества лингвистов, хотя это и не единственная точка зрения. Называя интонационный принцип «подчиненным», Т.И. Сурикова явно вторит Н.С. Валгиной, которая писала: «интонационный принцип действует в русской пунктуации как второстепенный»; «интонационный принцип, даже если он и действует, то в большинстве случаев не в чистом виде. Это значит, что какой-либо интонационный штрих (например, пауза), хотя и фиксируется знаком препинания, но в конечном счете сам является следствием заданного смыслового и грамматического членения предложения» [Valgina 1979]. Ту же мысль выражают и авторы статьи «Пунктуация» в «Лингвистическом энциклопедическом словаре», говоря, что «чаще этот [интонационный - М.Д.] принцип расценивают как дополнительный» [Karapetân, Švarckopf 1990: 407].

Явную диспропорцию между существующим знанием об интонации русского предложения и отсутствием учета этого знания в формулировках правил пунктуации почувствовали методисты. Недавно появилась работа [Kireeva 2016], автор которой утверждает, что «интонация и грамматика предложений (то есть форма речи) зависят друг от друга, поэтому во многих случаях интонационный и грамматический принципы постановки знаков препинания следует рассматривать как единый интонационно-грамматический принцип», предлагает читателям «интонационную модель предложения», вводит понятия темы и ремы и последовательно обращает внимание на их интонационное оформление, связывая его с пунктуацией. Детальный критический разбор 
этой работы не входит в наши задачи, но самый факт ее появления весьма показателен.

Каким же может быть учет существующих знаний об интонации русского предложения и, самое главное, что этот учет может дать правилам пунктуации? Обратимся к предложениям, в которых, согласно действующим правилам, ставится тире между составами подлежащего и сказуемого. В [Lopatin 2009] читаем:

§ 10. Между подлежащим и именным сказуемым на месте отсутствующей связки ставится тире, если подлежащее и сказуемое выражены существительными в форме именительного падежа: Флигель у дома на Садовой по проекту Михаила Александровича Врубеля - единственное строение из владений Мамонтовых, почти сохранивщее свой внешний вид до наших дней (Кис); Пушкинский край - край камней (Гейч.); Портрет этот - единственное живописное изображение дочери Анны Петровны Керн (Гейч.); ...Моя способность держать при себе прошлое черта наследственная (Наб.); И перегнувшаяся через забор женщина - твоя троюродная тетка (Щерб.).

Простейший анализ приведенных в параграфе примеров показывает, что в каждом из них состав подлежащего является в то же время и темой, а состав сказуемого - ремой. Соответствующим образом они и маркируются: тема - при помощи ИК-3, рема - при помощи ИК-1. Поскольку нас интересует только интонационное оформление фрагмента предложения, предшествующего тире, в примерах ниже отмечено только оно 2 . Полужирным шрифтом выделены акцентоносители темы:

(5) [Флигель у дома на Садовой по проекту М.А. Врубеля $]_{\mathrm{T}}-[$ [единственное строение из владений Мамонтовых, почти сохранивщее свой внешний вид до наших дней $]_{R}$;

(6) $[\text { Пушкинский край }]_{\mathrm{T}}-[\text { край камней }]_{\mathrm{R}}$;

(7) $\left[\text { Портрет }{ }_{0}{ }_{0} \text { тот }\right]_{\mathrm{T}}-[$ единственное живописное изображение дочери Анны Петровны Керн $]_{\mathrm{R}}$;

(8) $[\text { Моя способность держать при себе прошлое }]_{\mathrm{T}}-[\text { черта наследственная }]_{\mathrm{R}}$;

(9) $[\text { И перегнувшаяся через забор женщина Л }]_{\mathrm{T}}-[\text { твоя троюродная тетка }]_{\mathrm{R}}$.

В примечании к этому параграфу читаем:

Примечание. Тире может не ставиться, если в письменной речи отражено произношение с логическим ударением на сказуемом: Моя сестра учительница (ср.: Моя сестра - учительница - ударение и на слове сестра, и на слове учительнииа). Тире обязательно: 1) если имеется сопоставление: Моя сестра - учительница,

2 Используется уже ставшая традиционной нотация: « ${ }_{\Downarrow}$ и «\»- знаки коммуникативно значимых акцентов (соответственно, ИК-3, маркирующая тему, и ИК-1, маркирующая рему), нижним индексом “» помечается атонированный компонент коммуникативной структуры. Элементы нотации, обозначающие ИК, размещаются после компонента, несущего обозначаемый акцент. 
a брат - зоотехник; 2) если возможна синтаксическая или смысловая двусмысленность; ср.: Брат - мой учитель и Брат мой - учитель.

В этой формулировке любопытен, между прочим, фрагмент «если в письменной речи отражено произношение с логическим ударением на сказуемом»: с одной стороны, перед нами явная попытка учесть интонационное оформление предложения; с другой стороны, как такое произношение может быть отражено в письменной речи без использования диакритики и прочих графических способов акцентирования и выделения - непонятно. Вероятно, имелось в виду, что тире может не ставиться с целью подчеркивания логического ударения на сказуемом. Но суть дела не в этом, так как наличие логического ударения на сказуемом, в том числе и подчеркнутого, не может служить критерием, отличающим примеры основной части параграфа от примеров примечания. Критерий - в наличии / отсутствии ИК-3, маркирующей тему.

Первый из приведенных в этом примечании примеров при отсутствии тире, действительно, читается не так, как (5-9). Тема Моя сестра в нем атонирована, а предрематическая пауза отсутствует:

(10) ${ }_{0}[\text { Моя сестра }]_{\mathrm{T}}[\text { учительница } \searrow]_{\mathrm{R}}$.

При постановке же тире получаем стандартное оформление темы - или, что то же, при восстановлении стандартного акцента ИК-3 на теме возвращается и тире:

(11) $[\text { Моя сестра }]_{\mathrm{T}}-[\text { учительница } \searrow]_{\mathrm{R}}$.

Этот случай особенно убедительно показывает, что правила постановки тире в биноминативных предложениях теснейшим образом связаны с интонационным оформлением: пунктуационный знак и интонация взаимообусловлены, и изменение, связанное с одним из членов этой пары, неизбежно влечет изменение и второго члена. Думается, что приводить анализ остальных примеров из этого примечания избыточно; можно лишь заметить, что в последнем из них возникает атонирование элемента темы, поскольку акцентоноситель темы, Брат, смещен влево. Этот процесс описывается в [Padučeva 2015; Cimmerling 2016 и более ранние работы] как линейно-акцентное преобразование Сдвиг акцентоносителя темы влево (из стандартной для акцентоносителя финальной позиции в коммуникативной составляющей); при этом остальные компоненты коммуникативной составляющей, оказавшиеся справа от акцентоносителя, неизбежно атонируются:

(12) $\left[\text { Брат } \nearrow_{0} \text { мой }\right]_{\mathrm{T}}-[\text { учитель } \searrow]_{\mathrm{R}}$.

Таким образом, содержание $\S 10$ вместе с примечанием может быть отражено в следующей формулировке: при нулевой связке между подлежащим и именным сказуемым в именительном падеже ставится тире, если 


\section{состав подлежащего произносится с подъемом тона, а перед составом сказуемого делается краткая пауза.}

Следующий параграф регламентирует постановку тире при наличии слов вот и это:

§ 11. Тире ставится перед сказуемым, присоединяемым к подлежащему словами вот, это: «Уважение к минувшему - вот черта, отличающая образованность от дикости», - сказал когда-то Пушкин (Расп.); Пушкиногорье - это не только памятник историко-литературный, это и своеобразный ботанический и зоологический сад, замечательный памятник природы (Гейч.). В качестве связки возможно и сочетание это есть: Гипотенуза - это есть сторона прямоугольного треугольника, лежащая против прямого угла (из учебника).

Очевидно, что и в этом случае действует то же интонационное оформление; различие лишь в том, что наличие указанных в параграфе слов делает и ИК-3, и предрематическую паузу, и тире обязательными.

В следующем параграфе рассматриваются предложения с инфинитивом:

§ 12. Тире ставится при выражении и подлежащего, и сказуемого (или только подлежащего, или только сказуемого) инфинитивом: $B$ этом городе знать три языка - ненужная роскошь (Ч.); Ни с чем не сравнимое чувство - слышать их [грачей] в первый раз после шестимесячной зимней смерти! (Бун.). Наличие отрицания не снимает знака: Чай пить - не дрова рубить (посл.); Жизнь прожить - не поле перейти (посл.). То же, если в сказуемом имеются слова значит, это значит: Ждать разрешения - значит потерять время (газ.); Уйти сейчас из института - это значит потерять все (газ.); А понять человека - значит уже сочувствовать ему (Шукш.).

Альтернативное интонационное оформление, вызванное линейно-акцентным преобразованием, которое Е.В. Падучева называет экспрессивной препозицией (собственно) ремы [Padučeva 2015], наблюдается только в примере из И.А. Бунина (в круглых скобках приведен факультативный акцент):

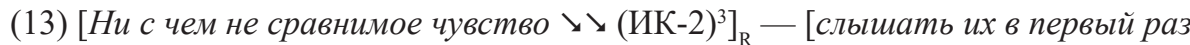

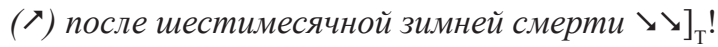

Особенно интересен, с наших позиций, § 15:

$\S$ 15. Тире между подлежащим и именным сказуемым не ставится: 1. Если подлежащее выражено личным или указательным местоимением: Она его дочь. Он хочет понять ее (Щерб.); Это кабинет? Это спальня? (Ч.)

Примечание. Тире возможно: а) если все предложение заключает в себе вопрос, сопровождаемый удивлением: Она - его дочь?! (оба члена предложения имеют

3 ИК-2 рассматривается как усиленный, эмфатический акцент ИК-1. 
ударение); б) при подчеркивании указания на данный предмет: Это - кабинет (И это - кабинет); в) при противопоставлении: Я - учитель, а ты -инженер.

Как видно из сочетания п. 1 и примечания, возможность тире открывается именно наличием того же интонационного оформления, что и в стандартных случаях вроде (5-9). Аналогичную картину наблюдаем и ниже, в п. 3 того же параграфа:

3. Если при сказуемом-существительном имеется отрицание: Пейзаж не довесок к прозе и не украшение (Пауст.); Россия не Петербург, она огромная (Пришв.); Старость не радость (посл.).

Однако при противопоставлении сказуемое с отрицанием требует постановки тире (не.. а): И в то же время замечал, что он-не господин в своем доме, а лишь составная часть его (М.Г.) (ср. без противопоставления: Он не господин в своем доме).

Как только состав подлежащего получает выраженное интонационное маркирование темы, тире становится обязательным.

В следующем пункте снова та же ситуация - и та же двучастная структура:

4. Если сказуемое выражено прилагательным или причастием: А твоя комната такая хорошая для ребенка (Ч.); У меня много хороших людей, почти все хорошие (Сим.); Две раны у него были. Раны нетрудные, но человек потерял много крови (Пауст.); Сруб розовый, облупившийся, по-деревенски маленький, покрытый зеленой железной крышей (Кав.); Суровой осени печален поздний вид (Забол.); В столовой пир горяч и пылок (Забол.).

Однако при сказуемом-прилагательном тире ставится при структурном параллелизме частей предложения, сопровождаемом в устной речи интонационным выделением (ударением) обоих членов предложения: Все в ее облике обращзало на себя внимание: взгляд-острый, прическа-мальчишеская, одежда-современная, модная; ср. при акцентном выделении только сказуемого: Погода несносная, дорога скверная, ямщик упрямый, лошади не везут, а виноват смотритель (П.). Тире возможно и при наличии нескольких (однородных) сказуемых: Cын у нее желтый, длинный и в очках (М.Г.).

Учет интонационного оформления конструкции позволяет суммировать содержание всех перечисленных параграфов с их подпунктами в следующей формулировке: при нулевой связке между подлежащим и именным сказуемым в именительном падеже ставится тире, если состав подлежащего произносится с подъемом тона, а перед составом сказуемого делается краткая пауза; при употреблении на месте нулевой связки слов вот, это, это есть, а также при выражении инфинитивом хотя бы одного из главных членов подъем тона, пауза и тире обязательны. Эта формулировка охватывает всё содержание рассмотренных выше параграфов.

Следует подчеркнуть, что предлагаемая ревизия формулировки правил не требует дополнительного введения в правила пунктуации новых понятий: вполне можно обойтись описательными номинациями темы, ремы, 
интонационных конструкций. Кроме того, в современных условиях крайне полезное и желательное сопровождение правил звучащими образцами чтения предложений-примеров не составит проблемы, и таким образом описание интонационного рисунка предложений получит надежное закрепление.

\section{Литература}

Ânko T.E., 2001, Kommunikativnye strategii russkoj reči, Moskva: Âzyki slavânskoj kul'tury. Bryzgunova E.A., 1980, Intonaciâ [in:] N.Û. Švedova (ed.), Russkaâ grammatika, Moskva: Nauka, vol. I.

Cimmerling A.V., 2016, Linejno-akcentnaâ grammatika i kommunikativno nerasčlenennye predloženiâ v russkom âzyke [in:] A.V. Cimmerling, E.A. Lûtikova (eds.), Arhitektura klauzy v parametričeskih modelâh: sintaksis, informacionnaâ struktura, porâdok slov, Moskva: Âzyki slavânskih kul'tur, pp. 76-103.

Divakova M.V., 2005, Principy punktuacii i normy sintaksičeskih postroenij russkogo literaturnogo âzyka pervoj treti XX veka: Avtoref. diss. [...] kand. filol. nauk, Moskva: MGOU, http://cheloveknauka.com/printsipy-punktuatsii-i-normy-sintaksicheskihpostroeniy-russkogo-literaturnogo-yazyka-pervoy-treti-xx-veka; 23.05.2020.

Fedorova L., 2010, Točka, točka, zapâtaâ..., Filolog: Internet-žurnal, iss. 10, http://philolog. pspu.ru/module/magazine/do/mpub_10_180; 23.05.2020.

Gaevskaâ T.I., 1973, Voprosy russkoj punktuacii v trudah grammatistov XVI-XVIII vekov: Posobie dlâ studentov, Perm': Permskij universitet.

Golubeva A., Gorbova Û., 2020, Edinitnaâ, udivnaâ, raz'âtnaâ..., Nauka i žizn', 5, pp. 86-92. Grot Â.K., 1894, Russkoe pravopisanie, Sankt-Peterburg: Imperatorskâa Akademiâ nauk. Grot Â.K., 1899, Spornye voprosy russkogo pravopisaniâ [in:] Trudy A.K. Grota. II. Filologičeskie razyskaniâ (1852-1892), Sankt-Peterburg.

Ivanov A.I., 1976, Maksim Grek kak učenyj na fone sovremennoj emu russkoj obrazovannosti, Bogoslovskie trudy XVI, Moskva: Izdatel'stvo Moskovskoj Patriarhii, pp. 142-187.

Karapetân G.K., Švarckopf B.S., 1990, Punktuaciâ [in:] V.N. Ârceva (ed.), Lingvističeskij ènciklopedičeskij slovar', Moskva: Sovetskaâ ènciklopediâ, pp. 406-407.

Kireeva N.P., 2016, Grammatičeskij metod obučeniâ russkomu pravopisaniû. Kn. 2. Lekcii po punktuacii, Moskva: Izdatel'skie rešeniâ, https://kartaslov.ru/книги/Киреева_Н_П_ Грамматический_метод_обучения_русскому_правописанию_Книга_2/1; 23.05.2020.

Lomonosov M.V., 1755, Rossijskaâ grammatika, Sankt-Peterburg: Imperatorskaâ Akademiâ nauk.

Lopatin V.V. (ed.), 2009, Pravila russkoj orfografii i punktuacii. Polnyj akademičeskij spravočnik, Moskva: AST-PRESS KNIGA.

Padučeva E.V., 2015, Kommunikativnaâ struktura predloženiâ [in:] Materialy dlâ proekta korpusnogo opisaniâ russkoj grammatiki (http://rusgram.ru), Moskva.

Peškovskij A.M., 1918, Rol' vyrazitel'nogo čteniâ v obučenii znakam prepinaniâ [in:] A.M. Peškovskij, Škol'naâ i naučnaâ grammatika, Moskva: Literaturno-izdatel'skij otdel Narodnogo komissariata po prosveŝeniû, pp. 107-127.

Reformatskij A.A., 1971/2018, Prolegomeny k izučeniû intonacii [in:] A.A. Reformatskij, Fonologiâ i morfonologiâ. Izbrannye raboty, Moskva: Ûrajt, pp. 99-151. 
Smotrickij M., 1619/2000, Grammatiki Slavenskiâ pravilnoe Sintagma [in:] E.A. Kuz'minova (ed.), Grammatiki Lavrentiâ Zizaniâ i Meletiâ Smotrickogo, Moskva: MGU (2000), pp. 129-470.

Surikova T.I., 2009, Russkij âzyk. Povtoritel'nyj kurs, Moskva: Al.'fa-M, Infra-M, http:// gramma.ru/RUS/?id=5.14; 23.05.2020.

Ŝerba L.V., 1935, Punktuaciâ [in:] Literaturnaâ ènciklopediâ: v 11 t. [M.], 1929-1939, vol. 9, Moskva: OGIZ RSFSR, Gos. in-t «Sov. Èncikl.», col. 366-370.

Valgina N.S., 1973, Sintaksis russkogo âzyka: Učebnik, Moskva: Vysšaâ škola, http://www. hi-edu.ru/e- books/xbook089/01/part-058.htm/; 1.07.2021.

Valgina N.S., 1979, Russkâ̂ punktuaciâ: principy i naznačenie. Posobie dlâ učitelej, Moskva: Prosveŝenie, http://genling.ru/books/item/f00/s00/z0000037/st007.shtml; 23.05.2020. 